\title{
Survival benefit of nephron-sparing surgery for patients with pT1b renal cell carcinoma: A population-based study
}

\author{
XIAODE LIU ${ }^{1,2}$, XUEMEI HUANG ${ }^{1,2}$, PAN ZHAO $^{2}$ and PENG ZHANG ${ }^{1}$ \\ ${ }^{1}$ Department of Urology, Institute of Urology, West China Hospital, Sichuan University; ${ }^{2}$ Department of Radiation Oncology, \\ Sichuan Cancer Center, Sichuan Cancer Hospital and Institute, School of Medicine \\ University of Electronic Science and Technology of China, Chengdu, Sichuan 610041, P.R. China
}

Received June 17, 2018; Accepted April 15, 2019

DOI: $10.3892 / \mathrm{ol} .2019 .11065$

\begin{abstract}
The use of partial nephrectomy (PN) to treat patients with large renal cell carcinoma (RCC) remains controversial, particularly among elderly patients. The present study compared the improvement in cancer-specific survival (CSS) in patients with pT1b RCC who underwent either PN or radical nephrectomy ( $\mathrm{RN})$ and investigated the effects of age and sex on CSS. A total of 20,343 patients were identified in the Surveillance, Epidemiology and End Results database. Kaplan-Meier curves and Cox regression analysis were used to compare the CSS of patients who received PN vs. those who received RN. In total, $5,375(26.42 \%)$ and 14,968 (73.58\%) patients with pT1b RCC received $\mathrm{PN}$ and $\mathrm{RN}$, respectively. Kaplan-Meier and Cox regression analysis indicated that PN resulted in an improved CSS compared with $\mathrm{RN}(\mathrm{P}<0.001)$. In addition, $\mathrm{PN}$ was observed to be beneficial in male $(\mathrm{P}<0.001)$ and female patients $<75$ years of age. However, it was not beneficial for female patients of $\geq 75$ years of age $(P=0.197)$. These preliminary results warrant further investigation in clinical trials.
\end{abstract}

\section{Introduction}

Renal cell carcinoma (RCC) accounts for $\sim 90 \%$ of all renal malignancies (1). For clinically localized RCC, nephrectomy remains the treatment method of choice (2). Numerous studies demonstrated that partial nephrectomy (PN) may provide a recurrence-free and long-term benefit to patients with tumors $<4 \mathrm{~cm}$ in diameter compared with radical nephrectomy ( $\mathrm{RN})$ (3-6). $\mathrm{PN}$ is thus becoming a main alternative to RN for treating T1a disease (RCC tumors $<4 \mathrm{~cm}$ ) (7-9), and the European Association of Urology (EAU) guidelines

Correspondence to: Professor Peng Zhang, Department of Urology, Institute of Urology, West China Hospital, Sichuan University, 37 Guoxuexiang Street, Chengdu, Sichuan 610041, P.R. China E-mail: zhangpenghuaxi@163.com

Key words: renal cell carcinoma, nephrectomy, partial nephrectomy, cancer-specific survival recommended $\mathrm{PN}$ as the standard surgical procedure for tumors measuring $<4 \mathrm{~cm}(10)$.

However, for tumors measuring $>4 \mathrm{~cm}$, the EAU guidelines do not recommend PN (10). Achieving patient benefit without damaging renal function is the most important purpose of RCC treatment. Mir et al (11) observed that PN may provide oncological outcomes similar to those of RN in clinical stage Tlb patients ( $\mathrm{RCC}$ tumors $\geq 4$ and $<7 \mathrm{~cm}$ ). In addition, other studies reported equivalent outcomes regarding cancer control (individuals with no disease recurrence or progression) for PN and RN (tumors $>4 \mathrm{~cm}$ ) $(12,13)$. The majority of those previous studies mostly focus on PN function, regardless of age. Tan et al (14) observed similar long-term survival in patients with T1 stage RCC who were treated with PN and $\mathrm{RN}$; however, subgroup analysis revealed improved survival in patients $>75$ years of age treated with PN compared with RN.

The purpose of the present study was to investigate the benefit of PN vs. RN on the cancer-specific survival (CSS) in patients with T1b RCC, and to further assess the effects of age and sex on the benefit of PN vs. RN. For that purpose, data from a population database were analyzed.

\section{Materials and methods}

Data source.Case details were retrieved from the Surveillance, Epidemiology, and End Results (SEER) database (https://seer. cancer.gov; code: kidney C64.9), which covers $28 \%$ USA population. The SEER program contains cancer epidemiology information (15).

Study population. Patients who were histologically confirmed to have RCC (stage pT1b N0M0) between the years 2004 and 2015 were identified using SEER*Stat software (version 8.3.2; https://seer.cancer.gov/data-software/). Variables including marital status, ethnicity, age at diagnosis, sex, surgical method, tumor size, laterality and months of follow-up were identified. TNM classification of RCC was based on the 6th edition of the American Joint Committee on Cancer staging system (16). In total, data from 20,554 patients with pT1b RCC who received PN or RN were collected. Patients of unknown ethnicity $(n=121)$, laterality $(n=4)$, tumor size $(n=5)$ or survival months $(n=67)$ were excluded. The remaining 20,343 patients were included in the present cohort study (Fig. 1). For data 
analysis, subgroups of patients were created as follows: Males $<75$ years; males $\geq 75$ years; females $<75$ years; and females $\geq 75$ years.

Statistical analysis. Frequencies and proportions were used to describe categorical variables. Means, medians and ranges were reported for continuous variables. The $\chi^{2}$ test was used to assess statistical significance in proportion differences, while the t-test was used to evaluate statistical significances in the means (Table I). The effect of surgery (PN vs. RN) on the CSS was evaluated by Kaplan-Meier survival curves with log-rank tests. Differences in CSS were assessed by multivariate Cox proportional hazards regression analyses. $\mathrm{P}<0.05$ was considered to indicate a statistically significant difference. Statistical analyses were performed using the statistical package MASS for R (version 3.4.1; https://www.r-project.org/) or Empower software version 1.1 (www.empowerstats.com).

\section{Results}

In total, 5,375 (26.42\%) and 14,968 (73.58\%) patients with pT1b RCC received PN and RN, respectively. The baseline characteristics of the patients are presented in Table I. Of all patients, $45.73 \%$ were diagnosed between 2004 and 2008 (mean follow-up time, 91 months), while 54.27\% were diagnosed between 2009 and 2015 (mean follow-up time, 35 months). The mean follow-up time was 92 months (range, 0-143 months) for PN and 90 months (range, 0-143 months) for RN. The mean overall age was 61.4 years [standard deviation (SD), 12.5 years], while the mean age for male patients was 61.2 years (SD, 12.1 years) and 61.7 years (SD, 13.0 years) for female patients.

Regardless of their age or sex, there was an improvement in CSS in all patients treated with $\mathrm{PN}(\mathrm{P}<0.001$; Fig. 2). There was an improvement in CSS in males $(\mathrm{P}<0.001)$ and females $(\mathrm{P}<0.001)$ regardless of their age. Multivariable Cox regression analyses revealed that PN was an independent predictor factor of CSS [hazard ratio (HR), 1.35; 95\% confidence interval (CI), 1.13-1.62; $\mathrm{P}=0.001)$. In addition, multivariate Cox regression analyses revealed that age at diagnosis, marital status, tumor size and grade were associated with outcomes (Table II).

Considering the age of the patients, male patients $<75$ and $\geq 75$ years of age exhibited an improvement in CSS following $\mathrm{PN}$ ( $\mathrm{P}=0.017$; Fig. 3). Among females, only patients $<75$ years exhibited a notable CSS improvement $(\mathrm{P}=0.002)$ following $\mathrm{PN}$. In patients treated by $\mathrm{PN} \geq 75$ years of age, no CSS improvement was observed ( $\mathrm{P}=0.197$; Fig. 4). Male and female patients $\geq 75$ years of age exhibited the same prognostic data for RN and PN, regardless of their sex (Fig. 5). All male and female patients $<75$ years exhibited improved CSS following PN. Female patients $<75$ years exhibited improved CSS following $\mathrm{PN}(\mathrm{P}=0.029)$ compared with male patients $<75$ years. There were no statistically significant differences for RN ( $\mathrm{P}=0.066$; Fig. 6).

The contradistinction of the follow-up of patients treated with PN (group 1, 2004-2008 and group 2, 2009-2015) is presented in Fig. $7(\mathrm{P}=0.091)$. The comparison of CSS following $\mathrm{PN}$ and $\mathrm{RN}$ during different periods of time is presented in Figs. 8 and 9 (Fig. 8, 2004-2008; $\mathrm{P}=0.002$; and Fig. 9, 2009-2015; $\mathrm{P}<0.001)$.

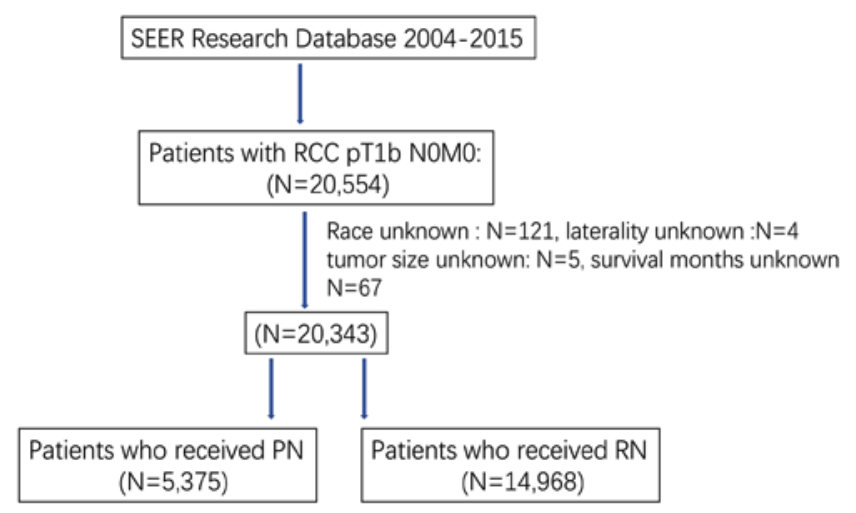

Figure 1. Consort flow diagram of patient selection in SEER. SEER, Surveillance, Epidemiology, and End Results; RCC, renal cell carcinoma; $\mathrm{RN}$, radical nephrectomy; PN, partial nephrectomy.

\section{Discussion}

The present study conducted a population-based analysis with 20,343 cases to compare the benefits of PN vs. RN in the treatment of pT1b RCC. The results obtained may clarify the benefit of PN and aid evidence-based surgical decision-making. Regardless of age and sex, a notable improvement in survival was observed for all patients treated with PN, compared with those treated with RN (HR, 1.35; $\mathrm{P}=0.001)$.

In terms of the improvement in CSS observed following $\mathrm{PN}$ in patients with $\mathrm{T} 1$ clinical stage RCC across all age groups, the results obtained in the current study are in accordance with the literature (17-19). Tan et al (14) reported improved survival only in patients with T1a RCC treated with PN who were $<75$ years of age. Previously, PN was considered to be associated with an increased probability of complications (20). Thus, elderly patients with multiple comorbidities were deemed to be more likely to suffer serious complications. However, according to a study by Roos et al (21), PN may be performed with acceptable complications on selected $\geq 65$-year-old patients with a single, small, unilateral, localized RCC. Similar studies revealed that selected $\geq 80$-year-old patients with RCC may benefit from PN (22-24). However, the aforementioned studies did not investigate the differences in the benefits of PN between age groups according to sex. In the current study, in the male group, patients $<75$ and $\geq 75$ years of age experienced an improved CSS $(\mathrm{P}=0.017)$ following PN compared with RN. Notably, in the female group, only patients $<75$ years of age exhibited a marked CSS improvement $(\mathrm{P}=0.002)$ following $\mathrm{PN}$ compared with $\mathrm{RN}$, which may be due to bias introduced by the small sample number. Dulabon et al (25) revealed that female patients had lower probability of undergoing PN compared with males, and that female patients, particularly the elderly, may prefer being subjected to active surveillance for renal disease rather than to surgical extirpation. In a previous study, PN decreased chronic kidney disease as well as nononcologic morbidity and mortality compared with $\mathrm{RN}$, and the complication rate did not differ between the young and old patients (26).

To exclude bias introduced by the implementation of new technologies, including laparoscopic robot-assisted procedures, compared with open surgery $(22,27,28)$, different time periods 
Table I. Baseline characteristics and pathological characteristics of patients.

\begin{tabular}{|c|c|c|c|}
\hline Characteristics & Partial nephrectomy & Radical nephrectomy & P-value \\
\hline $\mathrm{n}$ & $5,375(26.4 \%)$ & $14,968(73.6 \%)$ & \\
\hline Tumor size, (mm) & $50.9 \pm 7.6$ & $54.5 \pm 8.5$ & $<0.001$ \\
\hline Marital status, n (\%) & & & 0.211 \\
\hline Single/widowed/divorced/unmarried & $1,859(34.6 \%)$ & $5,319(35.5 \%)$ & \\
\hline Married & $3,516(65.4 \%)$ & $9,649(64.5 \%)$ & \\
\hline Age at diagnosis (years), n (\%) & & & $<0.001$ \\
\hline$\geq 75$ & $4,713(87.7 \%)$ & $12,446(83.2 \%)$ & \\
\hline$<75$ & $662(12.3 \%)$ & $2,522(16.8 \%)$ & \\
\hline Period diagnosed, n (\%) & & & $<0.001$ \\
\hline 2004-2008 & $1,545(28.7 \%)$ & $7,758(51.8 \%)$ & \\
\hline 2009-2015 & $3,830(71.3 \%)$ & $7,210(48.2 \%)$ & \\
\hline Sex, n (\%) & & & $<0.001$ \\
\hline Male & $3,600(67.0 \%)$ & $9,158(61.2 \%)$ & \\
\hline Female & $1,775(33.0 \%)$ & $5,810(38.8 \%)$ & \\
\hline Ethnicity, n (\%) & & & 0.001 \\
\hline Caucasian & $4,327(80.5 \%)$ & $12,337(82.4 \%)$ & \\
\hline African-American & $722(13.4 \%)$ & $1,726(11.5 \%)$ & \\
\hline Other (American Indian/AK Native, Asian) & $326(6.1 \%)$ & $905(6.1 \%)$ & \\
\hline Histology type, n (\%) & & & $<0.001$ \\
\hline Non-clear cell RCC & $2,457(45.7 \%)$ & $5,562(37.2 \%)$ & \\
\hline Clear cell RCC & $2,918(54.3 \%)$ & $9,406(62.8 \%)$ & \\
\hline Grade, $\mathrm{n}(\%)$ & & & $<0.001$ \\
\hline $\mathrm{I}+\mathrm{II}$ & $3,034(56.4 \%)$ & $8,939(59.7 \%)$ & \\
\hline III+IV & $1,561(29.1 \%)$ & $4,264(28.5 \%)$ & \\
\hline Unknown & $780(14.5 \%)$ & $1,765(11.8 \%)$ & \\
\hline Laterality, n (\%) & & & 0.170 \\
\hline Left & $2,612(48.6 \%)$ & $7,437(49.7 \%)$ & \\
\hline Right & $2,763(51.4 \%)$ & $7,531(50.3 \%)$ & \\
\hline
\end{tabular}

Statistical significance was determined by $\chi^{2}$ tests, with the exception of a t-test being used to determine statistical significance for tumor size.

Table II. Multivariable cox regression model in the cohort of patients with renal cell carcinoma.

\begin{tabular}{lcr}
\hline Variables & Hazard ratio $(95 \%$ confidence interval) & P-value \\
\hline Surgery type & $1.35(1.13-1.62)$ & 0.0010 \\
Marital status & $0.87(0.76-0.99)$ & 0.0370 \\
Age at diagnosis & $2.34(2.03-2.69)$ & $<0.0001$ \\
Period diagnosed & $0.87(0.75-1.02)$ & 0.0958 \\
Sex & $0.88(0.77-1.01)$ & 0.0698 \\
Ethnicity & & \\
Caucasian & Reference & \\
African-American & $1.01(0.83-1.24)$ & \\
Other (American Indian/AK Native, Asian) & $1.09(0.84-1.41)$ & 0.9126 \\
Histology type & $0.98(0.86-1.11)$ & \\
Grade & & 0.5207 \\
I+II & Reference & \\
III+IV & $1.97(1.72-2.24)$ & $<168$ \\
Unknown & $1.09(0.88-1.35)$ & 0.0001 \\
Laterality & $1.05(0.92-1.18)$ & 0.4355 \\
Tumor size & $1.03(1.02-1.04)$ & $<0.0001$ \\
\hline
\end{tabular}



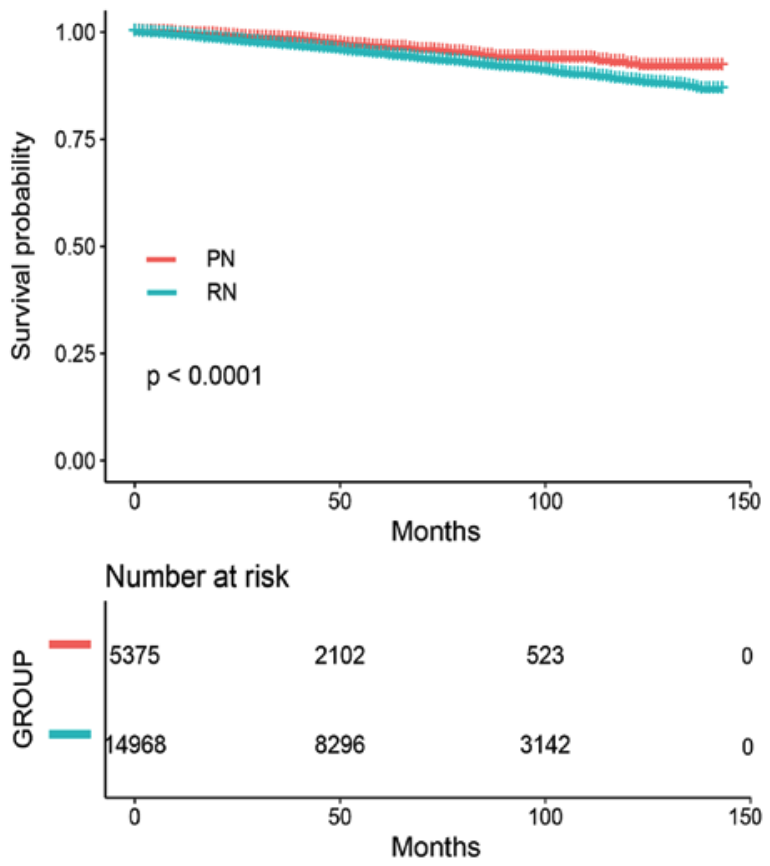

Figure 2. Cancer-specific survival of all patients with pT1b renal cell carcinoma following RN and PN. Regardless of their age or sex, there was an improvement in CSS in all patients treated with PN. RN, radical nephrectomy; PN, partial nephrectomy.
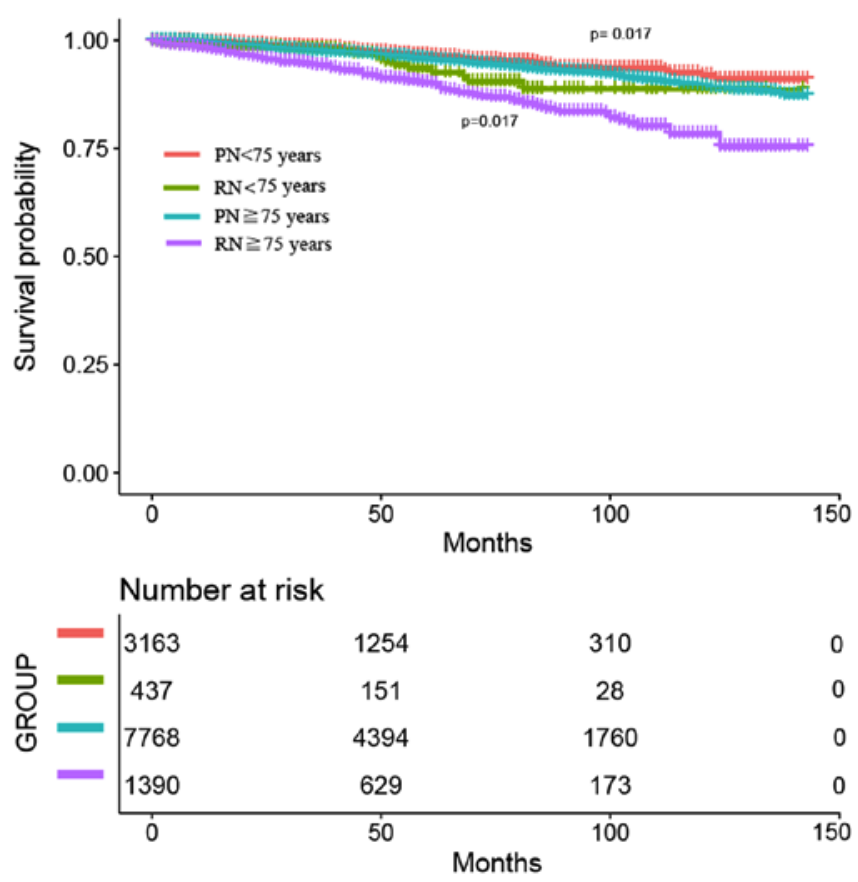

Figure 3. Cancer-specific survival of male patients $<75$ and $\geq 75$ years. Both male patients of $<75$ and $\geq 75$ years of age exhibited a CSS improvement. The P-value shown applies to the following comparisons: Male patients $<75$ treated by PN vs. treated by RN; male patients $\geq 75$ treated by PN vs. treated by RN. RN, radical nephrectomy; PN, partial nephrectomy.

were assessed for the PN group in the present study. Notable differences in CSS following PN were not observed between the groups treated during the periods 2004-2008 and 2009-2015 $(\mathrm{P}=0.091)$. According to these results, the implementation of new technologies had no effect on CSS following PN.
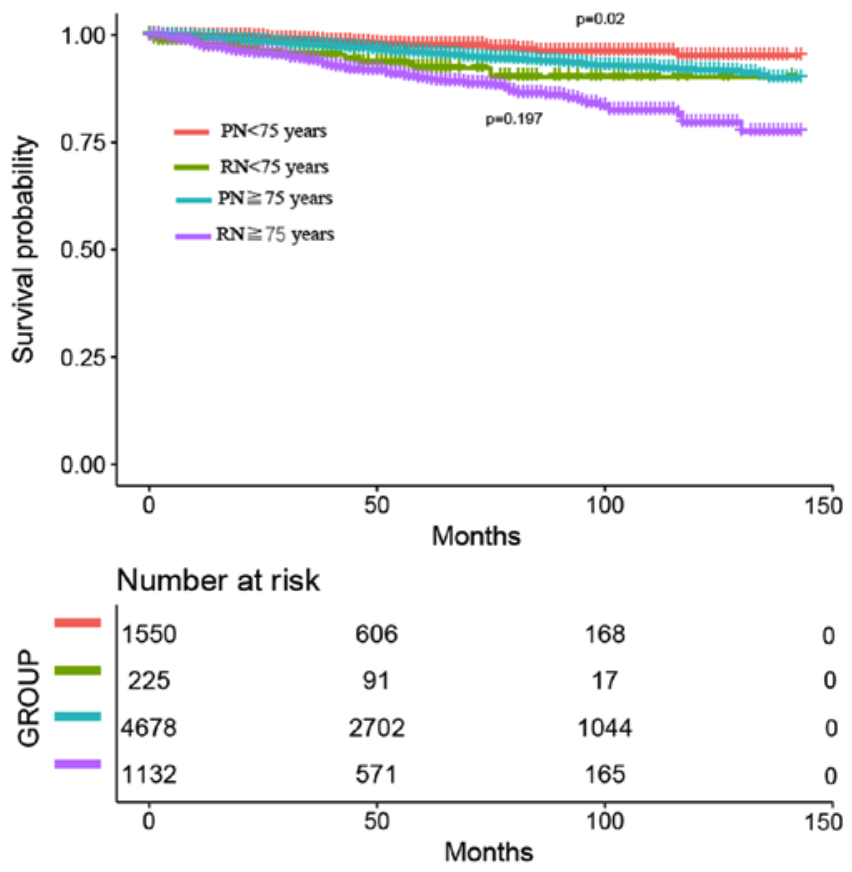

Figure 4. Cancer-specific survival of female patients $<75$ and $\geq 75$ years Patients of $<75$ years of age exhibited a notable CSS improvement upon PN. $\mathrm{RN}$, radical nephrectomy; PN, partial nephrectomy.

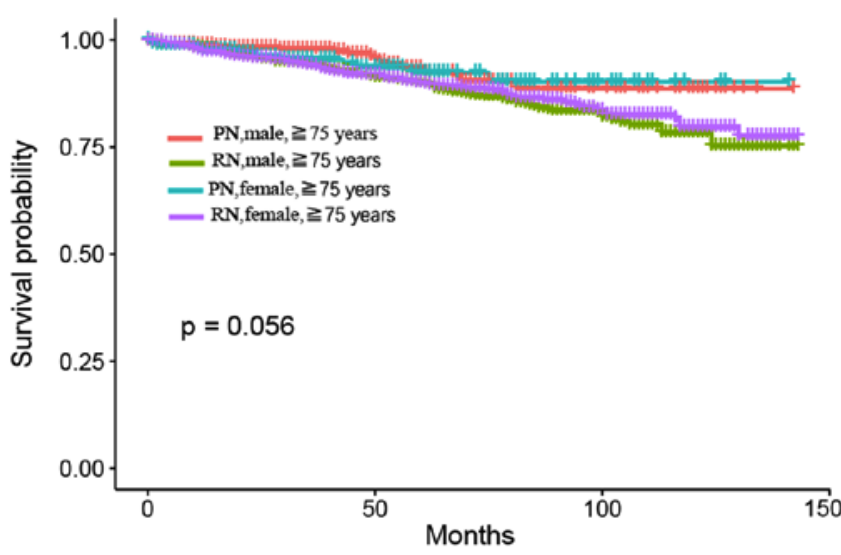

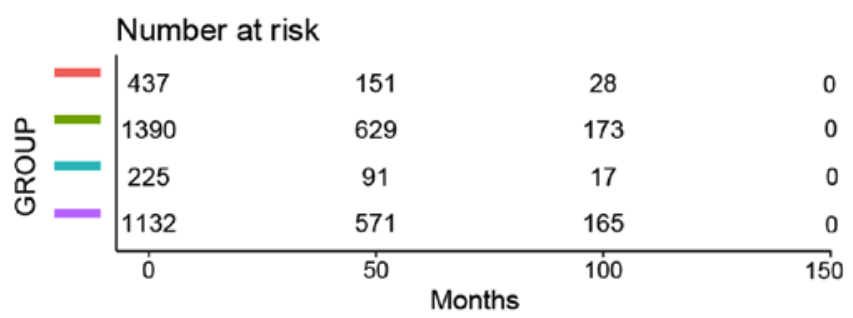

Figure 5. Cancer-specific survival of male and female patients $\geq 75$ years Male and female patients of $\geq 75$ years of age exhibited the same prognostic data for RN and PN. RN, radical nephrectomy; PN, partial nephrectomy.

A statistically significant improvement in CSS following PN was observed in patients treated during 2004-2008 who were followed up for a long period (mean follow-up time, 91 months; $\mathrm{P}=0.003$ ). This was also observed in patients treated during the 2009-2015 period (mean follow-up time, 35 months; $\mathrm{P}<0.001)$. Thus, it appears that CSS improvement following PN may not be associated with follow-up time. 

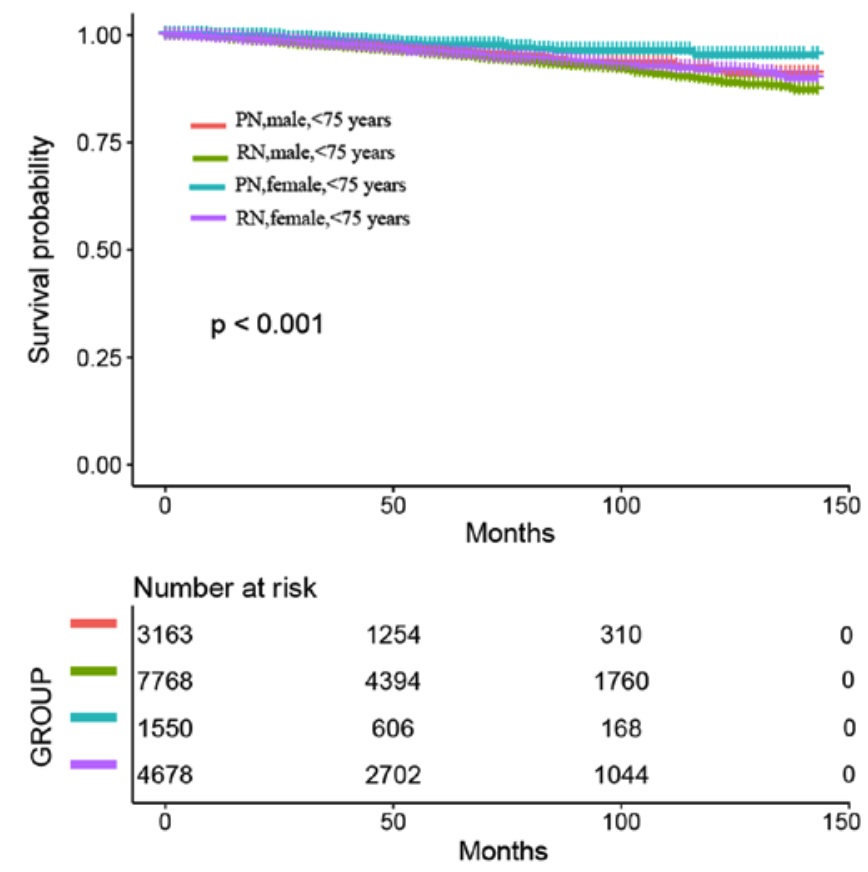

Figure 6. Cancer-specific survival of male and female patients $<75$ years. There were no statistically significant differences for RN. The P-value shown is the value obtained by comparing male patients $<75$ with the remaining groups. RN, radical nephrectomy; PN, partial nephrectomy.
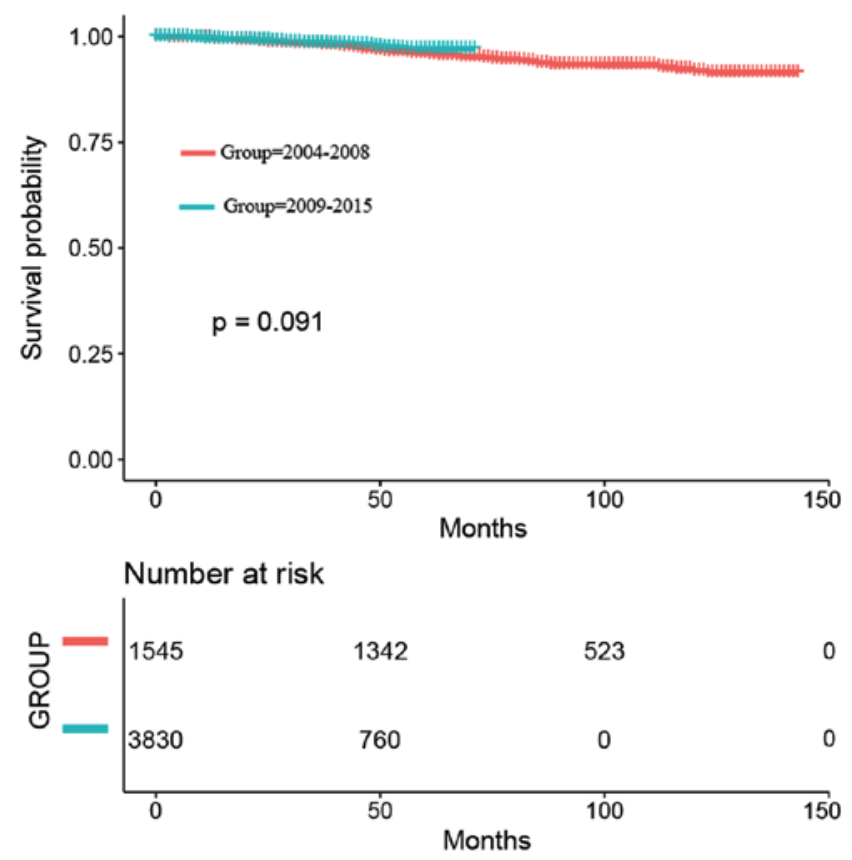

Figure 7. Cancer-specific survival of all patients with $\mathrm{pT} 1 \mathrm{~b}$ renal cell carcinoma following partial nephrectomy between 2004-2008 and 2009-2015. Notable differences in CSS upon PN were not observed between the groups treated during the periods 2004-2008 and 2009-2015. PN, partial nephrectomy.

Tobert et al (29) reported that loss of kidney function caused by surgery may have less effect on survival than chronic kidney disease (CKD). Thus, the protective role of PN against long-term complications such as cardiovascular disease in the elderly may be overestimated $(29,30)$. However, Huang et al (31) reported that patients who received PN had lower rates of damaging glomerular filtration rate and CKD
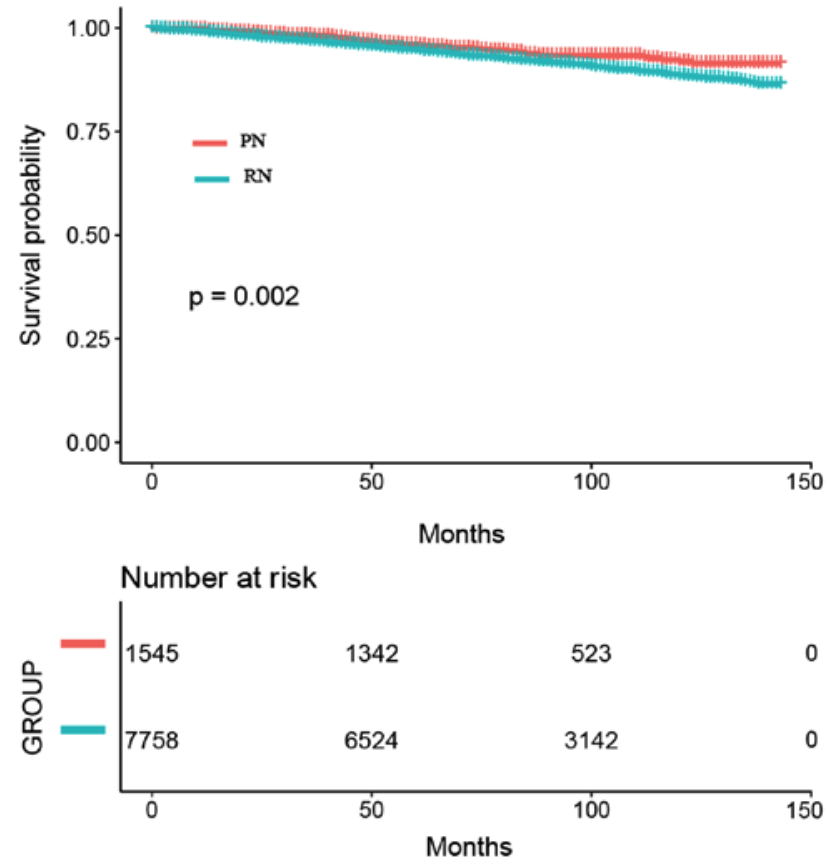

Figure 8. Cancer-specific of all patients with pT1b renal cell carcinoma following radical and partial nephrectomy during 2004-2008. A statistically significant CSS improvement upon PN was observed in patients treated during 2009-2015 period. PN, partial nephrectomy.
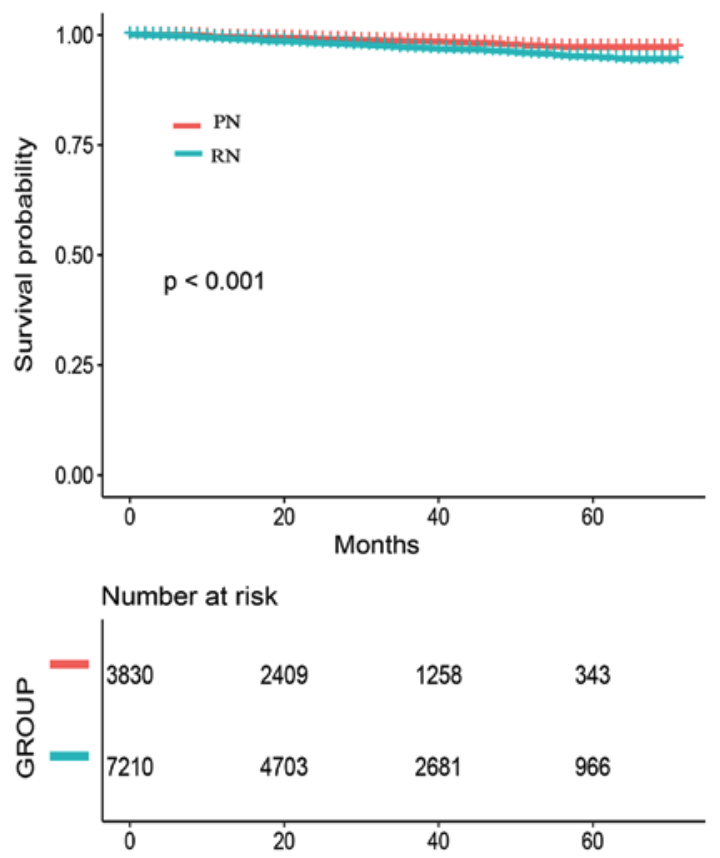

Figure 9. Cancer-specific survival of all patients with pT1b renal cell carcinoma following both radical and partial nephrectomy during 2009-2015. A statistically significant CSS improvement upon PN was observed in patients treated during 2009-2015 period. PN, partial nephrectomy.

than those receiving RN. However, other criteria, including tumor features, patients' wishes and social support, remain important when deciding to perform PN or RN surgery in elderly patients (21).

The present study had several limitations. The analyses were based on an observational study design, and this result obtained are limited by retrospective nature of the study. 
Moreover, the impact of competing risk bias on PN was not investigated (32). The SEER database does not contain information on preoperative renal function, which affects the selection of patients receiving partial resection. Since poor renal function is associated with increased risk of severe cardiovascular disease (33), if a large proportion of patients with poor preoperative renal function is included in the PN group, this may undervalue the role of PN. Furthermore, it is difficult to select appropriate patients to receive partial resection due to the absence of knowledge on the exact tumor location $(34,35)$.

Altogether, the results obtained in the present study, which was conducted on a large cohort, indicated that PN is beneficial for patients with pT1b RCC compared with RN. Future studies are required to clarify whether the patient age should be taken into account when planning to perform PN in patients with T1b RCC. According to the present study, female patients $\geq 75$ years of age appear to have limited benefit from PN. These results should be corroborated in clinical trials.

\section{Acknowledgements}

Not applicable.

\section{Funding}

The present study was supported by the 1.3.5 Project for Disciplines of Excellence, West China Hospital, Sichuan University (grant no. ZY2016104).

\section{Availability of data and materials}

The datasets analyzed during the present study were downloaded from the Surveillance, Epidemiology, and End Results (SEER) database (https://seer.cancer.gov; code: kidney C64.9).

\section{Authors' contributions}

PaZ and PeZ analyzed the data and confirmed the results' authenticity. XDL wrote the manuscript. XMH produced the tables and figures, and together with XDL, interpreted the results obtained. All authors read and approved the final manuscript.

\section{Ethics approval and consent to participate}

Not applicable.

\section{Patient consent for publication}

Not applicable.

\section{Competing interests}

The authors declare that they have no competing interests.

\section{References}

1. Siegel RL, Miller KD and Jemal A: Cancer statistics, 2017. CA Cancer J Clin 67: 7-30, 2017.
2. Motzer RJ, Jonasch E, Agarwal N, Bhayani S, Bro WP, Chang SS Choueiri TK, Costello BA, Derweesh IH, Fishman M, et al: Kidney cancer, version 2.2017, NCCN Clinical Practice Guidelines in Oncology. J Natl Compr Canc Netw 15: 804-834, 2017.

3. Crépel M, Jeldres C, Sun M, Lughezzani G, Isbarn H, Alasker A, Capitanio U, Shariat SF, Arjane P, Widmer H, et al: A population-based comparison of cancer-control rates between radical and partial nephrectomy for T1A renal cell carcinoma. Urology 76: 883-888, 2010.

4. Patard JJ, Shvarts O, Lam JS, Pantuck AJ, Kim HL, Ficarra V, Cindolo L, Han KR, De La Taille A, Tostain J, et al: Safety and efficacy of partial nephrectomy for all T1 tumors based on an international multicenter experience. J Urol 171: 2181-2185, quiz 2435, 2004

5. Danzig MR, Ghandour RA, Chang P, Wagner AA, Pierorazio PM, Allaf ME and McKiernan JM: Active surveillance is superior to radical nephrectomy and equivalent to partial nephrectomy for preserving renal function in patients with small renal masses: Results from the DISSRM registry. J Urol 194: 903-909, 2015.

6. Plante K, Stewart TM, Wang D, Bratslavsky G and Formica M: Treatment trends, determinants, and survival of partial and radical nephrectomy for stage I renal cell carcinoma: Results from the National Cancer Data Base, 2004-2013. Int Urol Nephrol 49: 1375-1381, 2017.

7. Touijer K, Jacqmin D, Kavoussi LR, Montorsi F, Patard JJ, Rogers CG, Russo P, Uzzo RG and Van Poppel H: The expanding role of partial nephrectomy: A critical analysis of indications, results, and complications. Eur Urol 57: 214-222, 2010.

8. Wang DC, Plante K, Stewart T, Wang D, Formica M, Daugherty M and Bratslavsky G: Comparison of survival for partial vs. radical nephrectomy in young patients with T1a renal cell carcinoma treated at commission on cancer-accredited facilities and influence of comorbidities on treatment choice. Urol Oncol 35: 660. e9-660.e15, 2017.

9. Larcher A, Sun M, Dell'Oglio P, Trudeau V, Boehm K, Schiffmann J, Tian Z, Fossati N, Capitanio U, Briganti A, et al: Mortality, morbidity and healthcare expenditures after local tumour ablation or partial nephrectomy for T1A kidney cancer. Eur J Surg Oncol 43: 815-822, 2017.

10. Ljungberg B, Bensalah K, Canfield S, Dabestani S, Hofmann F, Hora M, Kuczyk MA, Lam T, Marconi L, Merseburger AS, et al: EAU guidelines on renal cell carcinoma: 2014 update. Eur Urol 67: 913-924, 2015.

11. Mir MC, Derweesh I, Porpiglia F, Zargar H, Mottrie A and Autorino R: Partial nephrectomy versus radical nephrectomy for clinical T1b and T2 renal tumors: A systematic review and meta-analysis of comparative studies. Eur Urol 71: 606-617, 2017.

12. Badalato GM, Kates M, Wisnivesky JP, Choudhury AR and McKiernan JM: Survival after partial and radical nephrectomy for the treatment of stage T1bNOM0 renal cell carcinoma (RCC) in the USA: A propensity scoring approach. BJU Int 109: 1457-1462, 2012.

13. Hadjipavlou M, Khan F, Fowler S, Joyce A, Keeley FX and Sriprasad S: Partial vs. radical nephrectomy for T1 renal tumours: An analysis from the British Association of urological surgeons nephrectomy audit. BJU Int 117: 62-71, 2016.

14. Tan HJ, Norton EC, Ye Z, Hafez KS, Gore JL and Miller DC: Long-term survival following partial vs. radical nephrectomy among older patients with early-stage kidney cancer. JAMA 307: 1629-1635, 2012

15. Lin CC, Virgo KS, Robbins AS, Jemal A and Ward EM: Comparison of comorbid medical conditions in the National Cancer Database and the SEER-medicare database. Ann Surg Oncol 23: 4139-4148, 2016.

16. Greene FP, Page DL, Fleming ID, Fritz A, Balch CM, Haller DG and Morrow M (eds): AJCC Cancer Staging Manual. 6. Chicago: Springer-Verlag, 2002.

17. Weight CJ, Larson BT, Gao T, Campbell SC, Lane BR, Kaouk JH, Gill IS, Klein EA and Fergany AF: Elective partial nephrectomy in patients with clinical T1b renal tumors is associated with improved overall survival. Urology 76: 631-637, 2010.

18. Zini L, Perrotte P, Capitanio U, Jeldres C, Shariat SF, Antebi E, Saad F, Patard JJ, Montorsi F and Karakiewicz PI: Radical versus partial nephrectomy: Effect on overall and noncancer mortality. Cancer 115: 1465-1471, 2009.

19. Sun M, Bianchi M, Trinh QD, Hansen J, Abdollah F, Hanna N, Tian Z, Shariat SF, Montorsi F, Perrotte P and Karakiewicz PI: Comparison of partial vs. radical nephrectomy with regard to other-cause mortality in $\mathrm{T} 1$ renal cell carcinoma among patients aged $\geq 75$ years with multiple comorbidities. BJU Int 111: 67-73, 2013 . 
20. Novick AC: Laparoscopic and partial nephrectomy. Clin Cancer Res 10: S6322-S6327, 2004.

21. Roos FC, Brenner W, Jäger W, Albert C, Müller M, Thüroff JW and Hampel C: Perioperative morbidity and renal function in young and elderly patients undergoing elective nephron-sparing surgery or radical nephrectomy for renal tumours larger than $4 \mathrm{~cm}$. BJU Int 107: 554-561, 2011.

22. Roos FC, Pahernik S, Melchior SW and Thüroff JW: Renal tumour surgery in elderly patients. BJU Int 102: 680-683, 2008.

23. Thomas AA, Aron M, Hernandez AV, Lane BR and Gill IS: Laparoscopic partial nephrectomy in octogenarians. Urology 74 : 1042-1046, 2009.

24. Guzzo TJ, Allaf ME, Pierorazio PM, Miller D, McNeil BK, Kavoussi LR, Pavlovich CP and Schaeffer EM: Perioperative outcomes of elderly patients undergoing laparoscopic renal procedures. Urology 73: 572-576, 2009.

25. Dulabon LM, Lowrance WT, Russo P and Huang WC: Trends in renal tumor surgery delivery within the United States. Cancer 116: 2316-2321, 2010

26. Huang WC, Elkin EB, Levey AS, Jang TL and Russo P: Partial nephrectomy versus radical nephrectomy in patients with small renal tumors-is there a difference in mortality and cardiovascular outcomes? J Urol 181: 55-62, 2009.

27. Simmons MN, Chung BI and Gill IS: Perioperative efficacy of laparoscopic partial nephrectomy for tumors larger than $4 \mathrm{~cm}$. Eur Urol 55: 199-207, 2009.

28. Patel MN, Krane LS, Bhandari A, Laungani RG, Shrivastava A, Siddiqui SA, Menon M and Rogers CG: Robotic partial nephrectomy for renal tumors larger than $4 \mathrm{~cm}$. Eur Urol 57: 310-316, 2010.

29. Tobert CM, Riedinger CB and Lane BR: Do we know (or just believe) that partial nephrectomy leads to better survival than radical nephrectomy for renal cancer? World J Urol 32: 573-579, 2014.
30. An JY, Ball MW, Gorin MA, Hong JJ, Johnson MH, Pavlovich CP, Allaf ME and Pierorazio PM: Partial vs. radical nephrectomy for T1-T2 renal masses in the Elderly: Comparison of complications, renal function, and oncologic outcomes. Urology 100: 151-157, 2017.

31. Huang WC, Levey AS, Serio AM, Snyder M, Vickers AJ, Raj GV, Scardino PT and Russo P: Chronic kidney disease after nephrectomy in patients with renal cortical tumours: A retrospective cohort study. Lancet Oncol 7: 735-740, 2006.

32. Bianchi M, Gandaglia G, Trinh QD, Hansen J, Becker A, Abdollah F, Tian Z, Lughezzani G, Roghmann F, Briganti A, et al: A population-based competing-risks analysis of survival after nephrectomy for renal cell carcinoma. Urol Oncol 32: 46.e1-e7, 2014.

33. Capitanio U, Terrone C, Antonelli A, Minervini A, Volpe A, Furlan M, Matloob R, Regis F, Fiori C, Porpiglia F, et al: Nephron-sparing techniques independently decrease the risk of cardiovascular events relative to radical nephrectomy in patients with a T1a-T1b renal mass and normal preoperative renal function. Eur Urol 67: 683-689, 2015.

34. Becker F, Siemer S, Hack M, Humke U,Ziegler M and Stockle M: Excellent long-term cancer control with elective nephron-sparing surgery for selected renal cell carcinomas measuring more than $4 \mathrm{~cm}$. Eur Urol 49: 1058-1064, 2006.

35. Weight CJ,Larson BT,Fergany AF, Gao T,Lane BR,Campbell SC, Kaouk JH, Klein EA and Novick AC: Nephrectomy induced chronic renal insufficiency is associated with increased risk of cardiovascular death and death from any cause in patients with localized cT1b renal masses. J Urol 183: 1317-1323, 2010. 